\title{
Proceeding
}

Supplementary Issue: Autumn Conferences of Sports Science. Costa Blanca Sports Science Events, 18-19 December 2020. Alicante, Spain.

\section{Preventive effects of garlic and lemon extract combined with aerobic exercise on blood metabolic parameters and liver enzymes}

\author{
SARA TORKAMANEH ${ }^{1}$, JAVIER GENE-MORALES ${ }^{1,2}$, JORGE FLANDEZ ${ }^{3}$, MAHENDRA YADAV4, \\ MOHAMMAD SIDIQ ${ }^{5}$, MAHMOUD RAFIEIAN-KOPAEI $^{6}$, JUAN CARLOS COLADO ${ }^{1,7}$ \\ ${ }^{1}$ Research Unit in Sport and Health, University of Valencia, Valencia, Spain \\ 2Institute on Traffic and Road Safety (INTRAS), University of Valencia, Valencia, Spain \\ 3Institute of Education Sciences, Austral University of Chile, Ciudad de Valdivia, Chile \\ ${ }^{4}$ Department of Physiotherapy, Quality Care Medical Center, Abu Dhabi, United Arab Emirates \\ ${ }^{5}$ Rehabilitation Medicine Department, Northern Area Armed Forces Hospital King Khalid Military City, Saudi Arabia \\ ${ }^{6}$ Medical Plants Research Center, Shahrekord University of Medical Sciences, Sharekord, Islamic Republic of Iran \\ ${ }^{7}$ Department of Physical Education and Sports, University of Valencia, Valencia, Spain
}

\begin{abstract}
Purpose: The aim of this study was to evaluate the effects of aerobic exercise in combination with garlic and lemon on the lipid profile, metabolic parameters, and liver enzymes of obese male rats. Design: Sixty-four male Wistar rats were divided into eight equal groups consisting of 1) control following no treatment $(n=8) ; 2)$ hypercaloric fatty-food-based diet $(n=8)$; 3) aerobic exercise $(A E, n=8) ; 4)$ garlic intake $(G, n=8) ; 5)$ aerobic exercise with garlic intake $(A E G, n=8) ; 6)$ lemon intake $(L, n=8) ; 7)$ garlic and lemon ( $G L, n=8) ; 8)$ garlic, lemon and aerobic exercise (GLAE, $n=8)$. After six weeks of intervention, blood samples were taken to obtain cholesterol, triglycerides (TG), high-density lipoprotein cholesterol (HDL), low-density lipoprotein cholesterol (LDL), and glucose. C-reactive protein (CRP), alanine aminotransferase (GPT), aspartate aminotransferase (GOT), alkaline phosphatase (ALP), creatinine (Cr), urea and uric acid (UA) were also measured. A oneway ANOVA or the Kruskal Wallis tests for the non-normally distributed variables, with post-hoc pairwise comparisons were conducted to assess differences between groups. Results: All the intervention groups obtained significantly better values compared to the hypercaloric group, although being also fed with a hypercaloric diet. In certain parameters, the intervention groups obtained equal or even better results than the control healthy group. The combination of aerobic exercise with the intake of garlic and lemon showed slightly non-significant better results. Conclusion: Aerobic exercise combined with the intake of garlic and lemon juice may influence the lipid profile, liver enzymes, and other blood parameters associated with cardiovascular disease.

Keywords: Physical activity; Lipid profile; Hypercholesterolemia; Fatty liver; Cardiovascular disease; Wistar rats.

Cite this article as:

Torkamaneh, S., Gene-Morales, J., Flández, J., Yadav, M., Sidiq, M., Rafieian-Kopaei, M., \& Colado, J.C. (2021). Preventive effects of garlic and lemon extract combined with aerobic exercise on blood metabolic parameters and liver enzymes. Journal of Human Sport and Exercise, 16(2proc), S640-S650. doi:https://doi.org/10.14198/ihse.2021.16.Proc2.49

Corresponding author. Medical Plants Research Centre, Basic Health Science Institute, Shahrekord University of Medical Science. 8813833435, Sharekord, Islamic Republic of Iran. https://orcid.org/0000-0002-1860-1141

E-mail: rafieian@skums.ac.ir

Abstract submitted to: Autumn Conferences of Sports Science. Costa Blanca Sports Science Events, 18-19 December 2020. Alicante, Spain.

JOURNAL OF HUMAN SPORT \& EXERCISE ISSN 1988-5202

(C) Faculty of Education. University of Alicante

doi:10.14198/jhse.2021.16.Proc2.49
\end{abstract}

S640 | 2021| Proc2 | VOLUME 16

(C) 2021 University of Alicante 


\section{INTRODUCTION}

Cardiovascular disease (CVD) entails high rates of mortality (25-45\%; Mobaseri et al., 2003). Furthermore, when this disease is combined with factors such as obesity these mortality rates may increase three times (Aslani et al., 2015). It is important to control the levels in blood total cholesterol, triglycerides, very-lowdensity lipoprotein, low-density lipoprotein (LDL), and high-density lipoprotein (HDL) among other parameters within the management and prevention of CVD (Yang et al., 2011).

In this regard, regular exercise combined with appropriate nutritional intake is considered the best way to reduce obesity and control the aforementioned blood parameters (Shamsoddini et al., 2015; Wood et al., 1991). Previous expert literature has shown that regular physical activity increases HDL and lowers LDL, which is one crucial contribution to reducing the risk of cardiovascular disease (Kelley et al., 2019). Physical exercise has attracted the attention of many researchers in the field of cellular studies, particularly in the area of heart, brain, liver, muscle, and blood cells. Although physical exercise lowers fat and can be useful in the treatment of obesity, it is usually accompanied by an increase in oxidative stress, which is a risk factor to cell damage and breakdown (Ascensao et al., 2008). Aerobic exercise increases the efficiency of energy production systems and cardiorespiratory resistance. However, this exercise methodology performed at high intensities also increases the level of oxidative stress (Aslani et al., 2015), which can damage cellular DNA from various sources (Williamson and Davison, 2020). Oxidative stress plays a key role in obesity, and associated conditions such as dyslipidemia and hypertension, which are also risk factors for CVD (Marseglia et al., 2014).

One of the proposed treatments for increased oxidative stress is the intake of antioxidants. For instance, garlic supplementation has an important positive effect on hypercholesterolemia (Banerjee et al., 2002; Ried et al., 2008). Garlic (Allium sativum) has strong antioxidant properties and can therefore reduce oxidative stress due to its content in polyphenols. Garlic may also protect cells and metabolic tissues (e.g., liver) from chemical damage from peripheral toxins due to its contents in S-allyl-L-cysteine and propyl-cysteine, and also reduce lipid peroxidation through cysteine sulfoxides (Aslani et al., 2016; Dhawan \& Jain, 2004; Lanzotti et al., 2006). Furthermore, garlic has proven antimicrobial, antithrombotic, anticarcinogenic, antihypertensive, antiarthritic, and lipid and glucose-lowering properties (El-Sabban et al., 2009; Gorinsteina et al., 2006; Mohamed et al., 2011). Another nutritional supplement that is believed to play an important role in the prevention of cardiovascular diseases and oxidative stress is the lemon. Citrus limon, is one of the most popular fruit varieties worldwide. Previous studies have shown that the erycosytryn and hesperidin present in lemon juice can help in reducing oxidative stress due to their antioxidant properties (Aslani et al., 2015, 2016; Minato et al., 2003). Due to all these aforementioned facts, the question arises whether the specific combination of garlic and lemon supplementation altogether with aerobic exercise may play a role in parameters associated with CVD.

This study aimed at analysing the effects of aerobic exercise, the intake of garlic, lemon, and the combination of all these treatments on the lipid profile (triglycerides, HDL, LDL, cholesterol), metabolic parameters (glucose, creatinine, c-reactive protein [CRP], urea, uric acid [UA]), and liver enzymes (alkaline phosphatase [ALP], alanine aminotransferase [ALT], aspartate aminotransferase [AST]) in obese male rats. We hypothesized that the physical exercise altogether with the combination of garlic extract and lemon juice will improve to a greater extent the assessed parameters compared to the aforementioned treatments individually. 


\section{MATERIAL AND METHODS}

\section{Participants}

64 male Wistar rats (age: six weeks; average weight: $200 \mathrm{~g}$ ) were randomly assigned to eight experimental groups: [1] control $(n=8)$ following a normocaloric diet and no treatment; [2] hypercaloric $(n=8)$ following a high-fat diet and no treatment; [3] aerobic exercise $(A E, n=8)$ following a high-fat diet; [4] garlic extract intake $(G, n=8)$ following a high-fat diet and no exercise program; [5] garlic extract intake in combination with aerobic exercise (GAE, $n=8)$ and following a high-fat diet; [6] lemon juice intake $(L, n=8)$ following a highfat diet and no exercise program; [7] intake of garlic and lemon juice ( $G L, n=8)$ following a high-fat diet and no exercise program; [8] intake of garlic and lemon juice in combination with aerobic exercise (GLAE, $n=8)$ and following a high-fat diet. All the groups were homogeneous in terms of number, breed, age, and weight. All ethical considerations and working protocols of this study were approved by Shahrekord's committee for monitoring Laboratory Animal Rights in Medical Sciences University with code 2-1-94.

The rats were kept for six weeks in the Shahrekord University Animal Laboratory Medical Sciences at a temperature between 22 and $27^{\circ} \mathrm{C}$. The room was illuminated in a controlled manner (12 hours off and 12 hours on). All the groups ( $n=56$ ) were induced with hyperlipidemia and hypercholesterolemia by diet (see below "Diet formulation" section) and 8 rats remained healthy following a normocaloric diet (controls).

\section{Intervention}

\section{Diet formulation}

The selected 56 rats were daily fed by gavage with a specific diet to induce them with hypercholesterolemia and hyperlipidemia. More concretely, Persintra-M was prepared from egg yolk to induce hyperlipidemia ( $1 \mathrm{~g}$ of cholesterol, palm oil of $80 \%$ purity, and intralipid fluid per $100 \mathrm{~g}$ of egg yolk) and $25 \mathrm{mg}$ of cholesterol were condensed to $2 \mathrm{ml}$ to induce hypercholesterolemia. In addition, the rat's meal was brought to $1 \%$ cholesterol and $20 \%$ sugar using palm oil, sugar, and cow fat. The controls remained all the study with a normocaloric diet. Water was freely available to all the rats throughout the study.

\section{Aerobic training program}

The six-week (three sessions per week) aerobic training program was performed on a treadmill and was divided into three phases (two weeks of adaptation, two weeks of overload, and two weeks of maintenance/consolidation). A familiarization period was carried out before the resistance training program (see Table 1) to familiarize the rats with the materials and the procedures. All the phases used no inclination $\left(0^{\circ}\right)$. A 5-minute walk at $10 \mathrm{~m} / \mathrm{min}$ was used as a warm-up and cool-down in every session. The control group walked five minutes once per week at $10 \mathrm{~m} / \mathrm{min}$ and $0^{\circ}$ during the six weeks of the intervention.

To stimulate the rats to walk, an auditory stimulus (tapping on the wall of the treadmill) was used. For this purpose, a low-voltage electrical stimulus was initially used together with an audio stimulus. After the rats were conditioned to two stimuli simultaneously, the single audio stimulus was used in later sessions to comply with the ethics of animal experimentation.

Table 1. Aerobic training program.

\begin{tabular}{|c|c|c|c|c|c|c|}
\hline & \multicolumn{2}{|c|}{ Adaptation phase } & \multicolumn{2}{|c|}{ Overload phase } & \multicolumn{2}{|c|}{ Maintenance phase } \\
\hline & First week & Second week & Third week & Fourth week & Fifth week & Sixth week \\
\hline $\begin{array}{c}\text { Speed } \\
\text { Time }\end{array}$ & $\begin{array}{c}8 \mathrm{~m} / \mathrm{min} \\
10 \mathrm{~min}\end{array}$ & $\begin{array}{c}12 \mathrm{~m} / \mathrm{min} \\
20 \mathrm{~min}\end{array}$ & $\begin{array}{c}18 \mathrm{~m} / \mathrm{min} \\
30 \mathrm{~min}\end{array}$ & $\begin{array}{c}20 \mathrm{~m} / \mathrm{min} \\
40 \mathrm{~min}\end{array}$ & $\begin{array}{c}20 \mathrm{~m} / \mathrm{min} \\
40 \mathrm{~min}\end{array}$ & $\begin{array}{c}20 \mathrm{~m} / \mathrm{min} \\
40 \mathrm{~min}\end{array}$ \\
\hline
\end{tabular}


Garlic and lemon extraction and use

Samples of fresh garlic and lemon from authentic providers were prepared and used after confirmation from the University's Center for Herbal Medicine Research. To prepare the garlic extract, the fresh garlic was peeled and washed and then cut into smaller pieces with an electric mill (Moulinex, Osaka, Japan). The garlic was mixed with a dilution of $70 \%$ water and $30 \%$ alcohol and kept in the laboratory for 72 hours. It was then filtered, evaporated, and placed in an incubator at $37^{\circ} \mathrm{C}$ for three days. A dose of $200 \mathrm{mg} / \mathrm{kg}$ was dissolved in one $\mathrm{mL}$ of distilled water and given to each rat daily (Ebrahimi et al., 2015). To produce the lemon juice, after washing and squeezing the lemons, the extract was diluted with a juicer based on the concentration of $50 \mathrm{mg} / \mathrm{kg}$ from distilled water (Nichols et al., 2011).

\section{Measures}

After the six-week intervention, another session was used to extract the blood samples. The rats were anesthetized by an intraperitoneal injection of ketamine $(70 \mathrm{mg} / \mathrm{kg})$ and xylazine $(3-5 \mathrm{mg} / \mathrm{kg})$. Blood samples were taken from their hearts and were introduced in a Sigma centrifuge (Rontgen Co., Remscheid, Germany) at 5000 revolutions. At this point, the serum was transferred using Pars Azmoon kits (Pars Azmoon Co., Tehran, Iran) to a BT3000 analyser (Biotecnica Instrument S.p.A., Rome, Italy). Values of the lipid profile (triglycerides, HDL, LDL, cholesterol), metabolic parameters (glucose, creatinine, CRP, urea, UA), and liver enzymes (ALP, ALT, AST) were calculated.

\section{Data analysis}

After a basic data curation, the normality of the distribution and homogeneity of variances of each variable was assessed through the Shapiro-Wilk and Levene tests, respectively. Only the HDL and UA complied with normality and homoscedasticity assumption among the eight groups. Therefore, a one-way analysis of variance (ANOVA) for the normally distributed and Kruskal Wallis testing for the non-normally distributed variables were conducted. The effect size was reported as the eta squared $\left(\eta^{2}\right)$ where $0.01<\eta^{2}<0.06$ constitutes a small effect, $0.06 \leq \eta^{2} \leq 0.14$ a medium effect and $\eta^{2}>0.14$ constitutes a large effect. After this, paired post-hoc tests with Tukey adjustments for the parametric analysis and with no adjustment for the non-parametric evaluated significant differences. A 95\% confidence level (significance $p<.05$ ) was accepted as statistically significant. Statistical analysis was carried out using commercial software IBM SPSS Statistics for Macintosh (Version 26.0; IBM Corp., Armonk, NY). All data are reported as the means \pm the standard deviations and the $95 \%$ confidence interval.

\section{RESULTS}

Six weeks of fatty food diet were enough to significantly worsen almost all the variables in the hypercaloric group compared to the controls. The ANOVA and the Kruskal Wallis test indicated that significant differences existed among the study variables, with ALP: $H(7)=49.29, p<.001, \eta^{2}=0.76$; $A S T: H(7)=35.92, p<.001$, $\eta^{2}=0.52 ; \mathrm{ALT}: \mathrm{H}(7)=35.63, \mathrm{p}<.001, \eta^{2}=0.51 ; \mathrm{CRP}: \mathrm{H}(7)=28.55, \mathrm{p}<.001, \eta^{2}=0.39$; creatinine: $\mathrm{H}(7)$ $=27.16, p<.001, \eta^{2}=0.36$; UA: $F(7)=34.87, p<.001, \eta^{2}=0.71 ;$ urea: $H(7)=34.79, p<.001, \eta^{2}=0.50$; cholesterol: $\mathrm{H}(7)=39.94, \mathrm{p}<.001, \eta^{2}=0.59$; glucose: $\mathrm{H}(7)=44.65, \mathrm{p}<.001, \eta^{2}=0.67$; triglycerides: $\mathrm{H}(7)$ $=43.68, p<.001, \eta^{2}=0.66 ;$ LDL: $H(7)=31.84, p<.001, \eta^{2}=0.44 ;$ HDL: $F(7)=21.37, p<.001, \eta^{2}=0.60$. 
Table 2. Levels of liver enzymes (ALP, AST/GOT and ALT/GPT) and metabolic parameters (CRP, creatinine, UA and urea) in all experimental groups (all $n=8)$

\begin{tabular}{|c|c|c|c|c|c|c|c|}
\hline Group & ALP & AST & ALT & CRP & Creatinine & UA & Urea \\
\hline & $281.10 \pm 132.403,5,8$ & $97.12 \pm 7.82^{3,4,5,6,7}$ & $29.50 \pm 2.613,4,5,6,7$ & $15.05 \pm 1.53(3),(4),(5), 6$ & $0.47 \pm 0.04(8)$ & $2.95 \pm 0.43^{3,4,5,6,7}$ & $35.12 \pm 4.012,3,4,5,6,7,(8)$ \\
\hline 1 & [170.3-391.8] & [90.58-103.66] & [27.31-31.68] & [1376-16.33] & {$[.43-0.51]$} & [2.58-3.31] & [31.76-38.48] \\
\hline \multirow[t]{3}{*}{ (Control) } & Median: 2.42 & Median: 96.0 & Median: 30.00 & Median: 14.80 & Median: 0.50 & Median: 3.00 & Median: 34.00 \\
\hline & IQR: 224.00 & IQR: 10.00 & IQR: 4.47 & IQR: 2.95 & IQR: 0.07 & IQR: 0.45 & IQR: 4.50 \\
\hline & $823.00 \pm 146.20^{*}$ & $227.25 \pm 62.99^{*}$ & $60.75 \pm 7.99^{*}$ & $21.70 \pm 2.80^{*}$ & $0.78 \pm 0.12^{*}$ & $9.80 \pm 1.60^{*}$ & $62.25 \pm 12.20^{3,5,6,7,8}$ \\
\hline 2 & [700.7-945.2] & [147.58-279.91] & [54.06-67.43] & [19.35-24.04] & [0.68-0.89] & {$[8.45-11.14]$} & {$[52.04-72.45]$} \\
\hline \multirow[t]{3}{*}{ (Hyper) } & Median: 768.00 & Median: 191.50 & Median: 59.50 & Median: 31.15 & Median: 0.80 & Median: 9.50 & Median: 58.00 \\
\hline & IQR: 247.20 & IQR: 96.25 & IQR: 13.00 & IQR: 5.80 & IQR: 0.25 & IQR: 1.80 & IQR: 11.75 \\
\hline & $458.80 \pm 104.204,7$ & $132.37 \pm 18.66$ & $35.37 \pm 2.44$ & $16.48 \pm 0.80^{(8)}$ & $0.47 \pm 0.04^{(8)}$ & $4.65 \pm 0.72$ & $47.12 \pm 3.944$ \\
\hline 3 & [371.7-546.03] & [116.76-147.98] & [33.33-37.41] & [15.81-17.15] & {$[0.43-0.51]$} & [5.25-4.67] & [43.82-50.42] \\
\hline \multirow{3}{*}{$(\mathrm{AE})$} & Median: 448.00 & Median: 135.50 & Median: 35.00 & Median: 16.5 & Median: 0.50 & Median: 4.60 & Median: 48.00 \\
\hline & IQR: 150.75 & IQR: 35.50 & IQR: 4.75 & IQR: 1.57 & IQR: 0.07 & IQR: 0.67 & IQR: 5.00 \\
\hline & $234.50 \pm 33.83^{5,(6), 8}$ & $146.62 \pm 22.28{ }^{(8)}$ & $37.00 \pm 2.92^{(8)}$ & $16.70 \pm 0.99^{8}$ & $0.41 \pm 0.09$ & $4.48 \pm 0.89$ & $53.50 \pm 7.55^{8}$ \\
\hline 4 & [206.21-262.78] & [127.99-165.25] & [34.55-39.44] & [15.86-17.53] & [0.32-0.49] & [3.73-5.23] & [47.18-59.81] \\
\hline \multirow[t]{3}{*}{ (G) } & Median: 228.50 & Median: 146.00 & Median: 37.50 & Median: 16.30 & Median: 0.40 & Median: 4.25 & Median: 54.00 \\
\hline & IQR: 56.50 & IQR: 39.00 & IQR: 4.50 & IQR: 2.05 & IQR: 0.10 & IQR: 1.30 & IQR: 5.50 \\
\hline & $393.00 \pm 48.30^{7}$ & $127.62 \pm 23.95$ & $34.87 \pm 3.27$ & $16.32 \pm 1.54(8)$ & $0.45 \pm 0.09$ & $4.47 \pm 1.04$ & $53.62 \pm 7.89^{8}$ \\
\hline 5 & [352.5-433.2] & [107.59-147.65] & [32.14-37.60] & [15.03-17.61] & {$[0.37-0.52]$} & [3.60-5.34] & [47.02-60.22] \\
\hline \multirow[t]{3}{*}{ (GAE) } & Median: 410.00 & Median: 122.50 & Median: 34.50 & Median: 16.85 & Median: 0.45 & Median: 4.25 & Median: 53.50 \\
\hline & IQR: 80.00 & IQR: 46.00 & IQR: 2.75 & IQR: 2.35 & IQR: 0.10 & IQR: 1.40 & IQR: 9.50 \\
\hline & $339.80 \pm 24.21^{(7), 8}$ & $131.00 \pm 29.81$ & $35.00 \pm 4.00$ & $16.67 \pm 0.88^{8}$ & $0.47 \pm 0.08^{(8)}$ & $4.78 \pm 0.84$ & $50.25 \pm 7.47(7)$ \\
\hline 6 & [319.6-360.1] & [106.07-155.92] & [31.65-38.34] & [15.93-17.41] & [0.41-0.55] & [4.08-5.49] & [43.99-56.50] \\
\hline \multirow[t]{3}{*}{$(\mathrm{L})$} & Median: 344.50 & Median: 116.50 & Median: 34.50 & Median: 16.65 & Median: 0.50 & Median: 4.80 & Median: 47.50 \\
\hline & IQR: 32.00 & IQR: 53.00 & IQR: 5.00 & IQR: 1.35 & IQR: 0.17 & IQR: 1.45 & IQR:11.00 \\
\hline & $235.60 \pm 35.02^{8}$ & $138.37 \pm 31.13$ & $35.62 \pm 3.29$ & $16.05 \pm 1.07$ & $0.47 \pm 0.12$ & $4.82 \pm 1.03$ & $46.87 \pm 8.35$ \\
\hline 7 & [206.34-264.90] & [112.34-164.40] & [32.87-38.37] & [16.94-16.05] & [0.36-0.58] & [3.96-5.68] & [39.88-53.86] \\
\hline \multirow[t]{3}{*}{ (GL) } & Median: 223.50 & Median: 132.50 & Median: 35.50 & Median: 16.15 & Median: 0.45 & Median: 4.80 & Median: 47.00 \\
\hline & IQR: 58.50 & IQR: 61.00 & IQR: 6.25 & IQR: 1.83 & IQR: 0.61 & IQR: 1.85 & IQR: 16.50 \\
\hline & $510.80 \pm 65.50$ & $122.12 \pm 20.96$ & $33.62 \pm 3.29$ & $15.30 \pm 1.04$ & $0.38 \pm 0.09$ & $4.41 \pm 0.68$ & $44.62 \pm 3.24$ \\
\hline \multirow{3}{*}{$\begin{array}{c}8 \\
(G L A E)\end{array}$} & [456.09-565.65] & [104.59-139.65] & [30.87-36.37] & [15.15-16.94] & {$[0.30-0.47]$} & [3.83-4.98] & [41.90-47.34] \\
\hline & Median: 523.00 & Median: 118.50 & Median: 33.00 & Median: 16.15 & Median: 0.40 & Median: 4.20 & Median: 44.50 \\
\hline & IQR: 105.25 & IQR: 39.75 & IQR: 6.00 & IQR: 1.83 & IQR: 0.15 & IQR: 1.20 & IQR: 6.25 \\
\hline
\end{tabular}

Data are presented as mean \pm standard deviation and 95\% confidence interval for the mean [lower bound-upper bound]; median and interquartile range (IQR) are also displayed for the non-normal variables. Being *: significant difference $(p<.05)$ with all the rest of the groups; 1,2,3,4,5,6,7: significant difference with the group 1, 2, 3, 4, 5, 6, or 7, respectively (numbers between brackets represent statistical tendency at the level $0.5<p<1.3$ ); IQR: interquartile range; Hyper: hypercaloric group; AE: aerobic exercise group; G: garlic intake group; GAE: garlic intake combined with aerobic exercise group; L: lemon juice intake group; GL: garlic and lemon intake; GLAE: garlic and lemon intake combined with aerobic exercise; ALP: alkaline phosphatase; AST: aspartate aminotransferase; ALT: alanine aminotransferase; CRP: C-reactive protein; UA: uric acid. 
Table 3. Levels of lipid profile in all experimental groups (all $n=8)$.

\begin{tabular}{|c|c|c|c|c|c|}
\hline Group & Cholesterol & Glucose & Triglycerides & LDL & HDL \\
\hline & $54.75 \pm 3.01^{3,4,5,6,7}$ & $105.62 \pm 11.10^{3,(4), 5,6,7}$ & $26.62 \pm 6.412,3,(5), 6,7$ & $19.98 \pm 2.25^{2,3,(4), 5,6,7,8}$ & $44.33 \pm 4.20^{*}$ \\
\hline 1 & {$[52.23-57.26]$} & [96.3-114.9] & [21.26-31.98] & [17.82-22.09] & [40.82-47.85] \\
\hline \multirow[t]{3}{*}{ (Control) } & Median: 56.00 & Median: 103.50 & Median: 26.00 & Median: 19.57 & Median: 44.80 \\
\hline & IQR: 5.50 & IQR: 21.00 & IQR: 11.75 & IQR: 3.76 & IQR: 6.82 \\
\hline & $110.75 \pm 26.29^{*}$ & $218.00 \pm 22.27^{\star}$ & $148.37 \pm 26.51^{(3), 4,5,6,7,8}$ & $30.63 \pm 2.26^{*}$ & $29.17 \pm 0.73(4), 5,8$ \\
\hline 2 & [88.76-132.73] & [199.37-236.62] & [126.21-170.53] & [28.74-32.52] & [28.56-29.78] \\
\hline \multirow[t]{3}{*}{ (Hyper) } & Median: 106.50 & Median: 208.50 & Median: 156.00 & Median: 29.60 & Median: 29.00 \\
\hline & IQR: 19.50 & IQR: 24.25 & IQR: 51.50 & IQR: 4.18 & IQR: 1.20 \\
\hline & $65.5 \pm 8.40$ & $146.00 \pm 13.25^{8}$ & $60.00 \pm 16.2$ & $24.93 \pm 2.17$ & $31.52 \pm 3.27$ \\
\hline 3 & [58.47-72.52] & [134.91-157.08] & [46.44-73.55] & [23.11-26.75] & [28.78-34.26] \\
\hline \multirow[t]{3}{*}{$(A E)$} & Median: 66.50 & Median: 146.50 & Median: 63.50 & Median: 24.84 & Median: 31.10 \\
\hline & IQR: 8.00 & IQR: 17.25 & IQR: 29.25 & IQR: 2.75 & IQR: 6.57 \\
\hline & $66.125 \pm 4.61$ & $129.75 \pm 21.867$ & $35.62 \pm 12.80$ & $23.46 \pm 2.26$ & $33.27 \pm 2.40$ \\
\hline 4 & [62.26-69.98] & {$[111.47-148.02]$} & [24.86-46.38] & [21.56-25.35] & [31.26-3528] \\
\hline \multirow[t]{3}{*}{ (G) } & Median: 65.50 & Median: 126.50 & Median: 34.00 & Median: 23.35 & Median: 33.70 \\
\hline & IQR: 8.00 & IQR: 19.75 & IQR: 18.50 & IQR: 3.08 & IQR: 3.20 \\
\hline & $64.37 \pm 9.57^{(6),(7)}$ & $139.62 \pm 17.49(8)$ & $39.75 \pm 8.87$ & $24.00 \pm 2.08$ & $34.32 \pm 2.66$ \\
\hline 5 & [56.36-72.38] & [125.00-154.24] & [32.32-47.17] & [22.26-25.73] & [32.09-36.55] \\
\hline \multirow[t]{3}{*}{ (GAE) } & Median: 62.50 & Median: 144.00 & Median: 36.00 & Median: 24.15 & Median: 34.95 \\
\hline & IQR: 14.25 & IQR: 14.50 & IQR: 12.75 & IQR: 4.02 & IQR: 5.15 \\
\hline & $75.50 \pm 13.508$ & $148.00 \pm 23.85^{8}$ & $49.87 \pm 11.0$ & $24.53 \pm 2.08$ & $32.61 \pm 2.44[30.56-$ \\
\hline 6 & [64.21-86.78] & [128.05-167.94] & [40.66-59.08] & {$[24.86-46.38]$} & $34.65]$ \\
\hline \multirow[t]{3}{*}{$(\mathrm{L})$} & Median: 78.00 & Median: 139.50 & Median: 53.00 & Median: 22.79 & Median: 32.70 \\
\hline & IQR: 23.75 & IQR: 38.00 & IQR: 18.50 & IQR: 2.95 & IQR: 2.32 \\
\hline & $73.12 \pm 6.15^{8}$ & $155.25 \pm 11.65^{8}$ & $45.62 \pm 14.70$ & $25.00 \pm 2.70$ & $33.03 \pm 2.91$ \\
\hline 7 & [67.98-78.26] & [145.50-164.99] & {$[38.10-53.14]$} & [23.71-26.28] & $35.47]$ \\
\hline \multirow[t]{3}{*}{ (GL) } & Median: 72.00 & Median: 160.00 & Median: 45.50 & Median: 25.15 & Median: 33.10 \\
\hline & IQR: 8.25 & IQR: 16.00 & IQR: 14.75 & IQR: 3.27 & IQR: 3.27 \\
\hline & $60.87 \pm 5.35$ & $121.50 \pm 8.53$ & $35.25 \pm 4.50$ & $23.93 \pm 4.50$ & $36.18 \pm 2.28$ \\
\hline 8 & [56.39-65.35] & [114.36-128.63] & [31.65-38.84] & [21.64-26.22] & [34.27-38.09] \\
\hline \multirow[t]{2}{*}{ (GLAE) } & Median: 62.50 & Median: 122.50 & Median: 34.50 & Median: 23.45 & Median: 37.10 \\
\hline & IQR: 8.50 & IQR: 15.00 & IQR: 7.00 & IQR: 2.07 & IQR: 4.73 \\
\hline
\end{tabular}

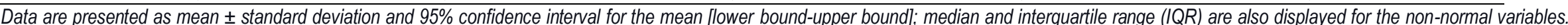

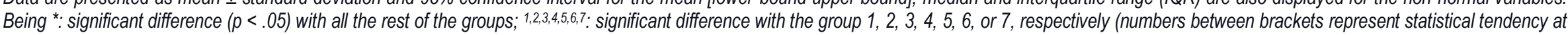

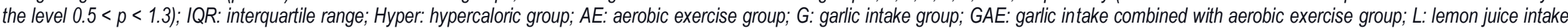
group; GL: garlic and lemon intake; GLAE: garlic and lemon intake combined with aerobic exercise; LDL: low-density lipoprotein; HDL: high-density lipoprotein. 


\section{DISCUSSION}

The main aim of this study was to analyse the potential preventive effect of garlic and lemon juice supplementation combined with aerobic exercise in the worsening of blood parameters (liver enzymes, metabolic parameters, and lipid profile) resultant from a hypercaloric diet. For such purpose, a control group was kept healthy and the rest of the groups followed a hypercaloric diet for six weeks. During these six weeks, six different treatments (i.e., aerobic exercise program; garlic supplementation; garlic supplementation and aerobic exercise; lemon juice supplementation; garlic and lemon juice supplementation; garlic and lemon juice supplementation combined with aerobic exercise) were applied to the rats and one group of rats received no treatment. It is worth highlighting that all the treatments served to prevent the worsening in almost all the assessed parameters (significant differences to the hypercaloric group), which confirms the study hypothesis. Furthermore, some values remained at the same levels as in the control healthy group, which followed a normocaloric diet. These findings suggest that the use of garlic and lemon supplementation combined with aerobic exercise may help in the prevention of hyperlipidemia and hypercholesterolemia, being both associated with obesity and risk factors for cardiovascular disease.

In line with these findings, previous research has reported preventive effects of garlic, lemon, and aerobic exercise in fatty liver, atherosclerosis, and metabolic syndrome (Aslani et al., 2016; Batsis \& Lopez-Jimenez, 2010; Sohn et al., 2012). Therefore, the use of herbal medicines altogether with aerobic exercise can be a good alternative to chemical medicines (Rahman et al., 2003). Fatty acid synthesis such as HDL and reduction in cholesterol absorption may be possible mechanisms of action. Previous studies have reported similar beneficial effect with the garlic supplementation in the lipid profile (Banerjee \& Maulik, 2002; Budoff et al., 2009; Durak et al., 2004; Mohammadi \& Oshaghi, 2014), with other studies obtaining controversial results in the lipid profile (Turner et al., 2004) and glucose reduction (Ali et al., 2000). Also, the lemon has been associated with hepatoprotective properties (Bhavsar et al., 2007; Minato et al., 2003). The mixture of garlic with lemon juice has been highlighted as a potential supplementation therapy to non-alcoholic fatty liver, which is a disease characterized by hyperlipidemia and liver enzyme imbalance (Berman et al., 2017; Shi et al., 2012; Xu et al., 2020). All these positive effects of garlic and lemon supplementation can be enhanced with the addition of aerobic exercise, as shown in our results.

Exercise alone or in combination with garlic and lemon supplementation, can be useful in the treatment of patients suffering from obesity (Warshafsky et al., 1993) and fatty liver (Torkamaneh et al., 2016). Physical activity increases the secondary messenger substances in the skeletal muscles, which leads to better glucose consumption and a reduction in insulin resistance (Kim et al., 2017). Studies in humans and rodents show that exercise has a positive effect on fatty liver and liver functions independent of weight reduction. Exercise increases the activity of the liver glucagon, a stimulant for the glucose-producing pathways. The exerciseinduced increase in glucagon activity is also responsible for some changes in the expression of those liver genes that are compatible with the increase in fat oxidation (Shamsoddini et al., 2015). All these properties of the exercise help in the control of hyperlipidemia and hypercholesterolemia among other benefits. In line with our results in terms of liver enzymes reduction, Shamsoddini et al. (2015) reported exceptional liver enzyme and liver fat decreases with aerobic exercise. On the other hand, exercise at high intensities may produce oxidative stress (Ascensao et al., 2008). In this regard, garlic extract and lemon juice have proven beneficious to enhance antioxidant potential against exercise-induced oxidative stress, in part by modulating the activity of oxidizing enzymes, which may also serve as a beneficial agent on cardiovascular disease (Yoon et al., 2006). Due to all these aforementioned factors and their relation, it could be recommended the combination of aerobic exercise with natural herb supplementation with antioxidant properties such as garlic and lemon juice looking forward to improving the values of certain blood parameters associated with obesity 
and cardiovascular disease progression (e.g., hyperlipidemia, hypercholesterolemia) such as those included in this research.

\section{CONCLUSION}

Supported on the results obtained, this study argues strongly in favour of the use of aerobic exercise and herbal supplementation such as garlic and lemon in the prevention of acquired obesity or cardiovascular disease and related factors such as hyperlipidemia or hypercholesterolemia. The combination of exercise and garlic and lemon intake showed slightly (non-significantly in many cases) better results than their isolated use, which suggests that their combination could provide additional benefits and that further research is needs on this matter.

\section{ACKNOWLEDGMENTS}

The authors gratefully acknowledge the cooperation of the Shahrekord Medicinal Plants Research Center, which supported and funded this project. We would also like to thank all the research staff members who participated in the present study.

\section{REFERENCES}

Ali M., Al Qattan K. K., Al Enezi F., Khanafer R. M., \& Mustafa T. (2000). Effect of allicin from garlic powder on serum lipids and blood pressure in rats fed with a high cholesterol diet. Prostaglandins Leukot Essent Fatty Acids, 62(4), 253-259. https://doi.org/10.1054/plef.2000.0152

Ascensao, A., Rebelo, A., Oliveira, E., Marques, F., Pereira, L., \& Magalhaes, J. (2008). Biochemical impact of a soccer match-analysis of oxidative stress and muscle damage markers throughout recovery. Clinical Biochemistry, 41(10-11), 841-851. https://doi.org/10.1016/i.clinbiochem.2008.04.008

Aslani, N., Entezari, M., Maghsoudi, Z., \& Askari, G. (2015). Effect of garlic and lemon juice mixture on fasting blood sugar, diastolic and systolic blood pressure and body mass index in people with hyperlipidemia. Journal of Isfahan Medical School, 32, 320, 2491-2500.

Aslani, N., Entezari, M. H., Askari, G., Maghsoudi, Z., \& Maracy, M. R. (2016). Effect of garlic and lemon juice mixture on lipid profile and some cardiovascular risk factors in people 30-60 years old with moderate hyperlipidaemia: A randomized clinical trial. International Journal of Preventive Medicne, 7, 95. https://doi.org/10.4103/2008-7802.187248

Aucott, L., Poobalan, A., Smith, W. C., Avenell, A., Jung, R., Broom, J., \& Grant, A. M. (2004). Weight loss in obese diabetic and non-diabetic individuals and long-term diabetes outcomes - a systematic review. Diabetes Obesity and Metabolism, 6, 85-94. https://doi.org/10.1111/j.14628902.2004.00315.x

Banerjee, S. K., \& Maulik, S. K. (2002). Effect of garlic on cardiovascular disorders: a review. Nutrition Journal, 1(4). https://doi.org/10.1186/1475-2891-1-4

Batsis, J. A., \& Lopez-Jimenez, F. (2010).Cardiovascular risk assessment - From individual risk prediction to estimation of global risk and change in risk in the population. BMC Med;8:29. https://doi.org/10.1186/1741-7015-8-29

Berman, A. Y., Motechin, R. A., Wiesenfeld, M. Y., \& Holz, M. K. (2017). The therapeutic potential of resveratrol: a review of clinical trials. NPJ Precision Oncology, 35. https://doi.org/10.1038/s41698$\underline{017-0038-6}$ 
Bhavsar, S. K., Joshi, P., Shah, M. B., \& Santani, D. D. (2007). Investigation into hepatoprotective activity of Citrus limon. Pharmaceutical Biology, 45(4), 303-311. https://doi.org/10.1080/13880200701214995

Budoff, M. J., Ahmadi, N., Gul, K. M., Liu, S. T., Flores, F. R., Tiano, J., et al. (2009). Aged garlic extract supplemented with $B$ vitamins, folic acid and $L$ arginine retards the progression of subclinical atherosclerosis: a randomized clinical trial. Preventive Medicine, 49(2,3),101-107. https://doi.org/10.1016/i.ypmed.2009.06.018

Dhawan, V., \& Jain S. (2004). Effect of garlic supplementation on oxidized low-density lipoproteins and lipid peroxidation in patients of essential hypertension. Molecular and Cellular Biochemistry 266, 109115. https://doi.org/10.1023/B:MCBI.0000049146.89059.53

Durak, I., Kavutcu, M., Aytaç, B., Avci, A., Devrim, E., Ozbek, H., \& Öztürka, H. S. (2004). Effects of garlic extract consumption on blood lipid and oxidant/antioxidant parameters in humans with high blood cholesterol. The Journal of Nutritional Biochemistry, 15(6), 373. https://doi.org/10.1016/i.jnutbio.2004.01.005

Ebrahimi, T., Behdad, B., Abbasi, M. A., Rabati, R. G., Fayyaz, A. F., Behnod, V., \& Asgari, A. (2015). High doses of garlic extract significantly attenuated the ratio of serum LDL to HDL level in rat-fed with hypercholesterolemia diet. Diagnostic Pathology, 10(1), 74. https://doi.org/10.1186/s13000-015$\underline{0322-0}$

El-Sabban, F. (2009). Garlic as an antithrombotic and antiplatelet aggregation agent. Journal of Chinese Clinical Medicine, 4(5), 288-294.

Folsom, A., Arnett, D., Hutchinson, R., Liao, F., Clegg, L. X., \& Cooper, L. S. (1997). Physical activity and incidence of coronary heart disease in middle-aged women and men. Medicine \& Science in Sports \&Exercise; 29(7), 901-907. https://doi.org/10.1097/00005768-199707000-00009

Gorinsteina, S., Leontowiczb, M., Leontowiczb, H., Najmanb, K., Namiesnikc, J., Park, Y. S., Jung, S., Kang, S., \& Trakhtenberg, S. (2006). Supplementation of garlic lowers lipids and increases antioxidant capacity in plasma of rats. Nutrition Research, 26(7), 362-368. https://doi.org/10.1016/i.nutres.2006.06.008

Hsu, C. C., Lin, C. C., Liao, T. S., Yin, M. C. (2006). Protective effect of s-allyl cysteine and spropylcysteine on acetaminophen-induced hepatotoxicity in mice. Food and Chemical Toxicology, 44(3), 393-397. https://doi.org/10.1016/j.fct.2005.08.012

Kelley, G. A., Kelley, K. S., \& Pate, R. R. (2019). Exercise and adiposity in overweight and obese children and adolescents: a systematic review with network meta-analysis of randomised trials. BMJ Open, 9(11), e031220. https://doi.org/10.1136/bmjopen-2019-031220

Lanzotti, V. (2006). The analysis of onion and garlic. Journal of Chromatography A, 1112(1-2), 3-22. https://doi.org/10.1016/i.chroma.2005.12.016

Marseglia, L., Manti, S., D'Angelo, G., Nicotera, A., Parisi, E., Di Rosa, G., Gitto, E., \& Arrigo, T. (2014). Oxidative stress in obesity: a critical component in human diseases. International journal of molecular sciences, 16(1), 378-400. https://doi.org/10.3390/ijms 16010378

Matsuura, H. (2001). Saponins in garlic as modifiers of the risk of cardiovascular disease. The Journal of Nutrition, 131(3),1000S-1005S. https://doi.org/10.1093/in/131.3.1000S

Minato, K., Miyake, Y., Fukumoto, S., Yamamoto, K., Kato, Y., Shimomura, Y., Osawa, T. (2003). Lemon flavonoid, eriocitrin, suppresses exercise-induced oxidative damage in rat liver. Life Sci. 21; 72(14):1609-16. https://doi.org/10.1016/S0024-3205(02)02443-8

Mobasseri, M., Fakhrzadeh, H., Pourebrahim, R., Nouri, M., Shoushtarizade, P., \& Pajuhi, M. (2003). Evaluation of lipid abnormalities in urban population 25-64 years-old in Tehran University of Medical Sciences (population lab region). Iranian Journal of Diabetes and Lipid Disorders, 3(1), 53-62. [In Persian]. 
Mohamed, M. S., Abdel-Kader, M. M., \& Kassem, S. S. (2011). Effect of dietary garlic and onion on liver and tibial mineral concentrations in omega-3 fatty acids rich oil fed rats. Agriculture and Biology Journal of North America, 2(5), 745-51. https://doi.org/10.5251/abjna.2011.2.5.745.751

Mohammadi, A., \& Oshaghi, EA. (2014). Effect of garlic on lipid profile and expression of LXR alpha in intestine and liver of hypercholesterolemic mice. Journal of Diabetes \& Metabolic Disorders, 13(20). https://doi.org/10.1186/2251-6581-13-20

Namjoo, A., Heidarian, E., Rafieian-Kopaei, M., \& Jafarian-Dehkordi, M. (2013). Effect of chronic oral administration of garlic aqueous extract on tissue changes, some blood and enzymatical parameters in male rats. Journal of Shahrekord University of Medical Science, 15(1), 103-113. http://journal.skums.ac.ir/article-1-1474-en.html

Nichols, L. A., Jackson, D. E., Manthey, J. A., Shukla, S. D., \& Holland, L. J. (2011). Citrus flavonoids repress the mRNA for stearoyl-CoA desaturase, a key enzyme in lipid synthesis and obesity control, in rat primary hepatocytes. Lipids in Health and Disease, 10(1), 36. https://doi.org/10.1186/1476511X-10-36

Rahman, K. (2003). Garlic and aging: new insights into an old remedy. Ageing Research Reviews, 2(1), 39-56. https://doi.org/10.1016/S1568-1637(02)00049-1

Ried, K., Frank, O. R., Stocks, N. P., Fakler, P., \& Sullivan, T. (2008). Effect of garlic on blood pressure: A systematic review and meta-analysis. BMC Cardiovascular Disorders, 8(1), 13. https://doi.org/10.1186/1471-2261-8-13

Shamsoddini, A., Sobhani, V., Ghamar Chehreh, M. E., Alavian, S. M., \& Zaree, A. (2015). Effect of aerobic and resistance exercise training on liver enzymes and hepatic fat in iranian men with nonalcoholic fatty liver disease. Hepatitis Monthly, 15(10), e31434. https://doi.org/10.5812/hepatmon.31434

Shi, K. Q., Fan, Y. C., Liu, W. Y., Li, L. F., Chen, Y. P., \& Zheng, M. H. (2012). Traditional Chinese medicines benefit to nonalcoholic fatty liver disease: a systematic review and meta-analysis. Molecular Biology Reports, 39, 9715-9722. https://doi.org/10.1007/s11033-012-1836-0

Sohn, C. W., Kim, H., You, B. R., Kim, M. J., Kim, H. J., Lee, J. Y, \& Kim, M. R. (2012). High temperatureand high pressure-processed garlic improves lipid profiles in rats fed high cholesterol diets. Journal of Medicinal Food, 15(5), 435-440. https://doi.org/10.1089//mf.2011.1922

Torkamaneh, S., Sharifi, GH., \& Rafieian, M. (2016). The comparison between effects of Berberis vulgaris Extract and aerobic exercise on none-alcoholic fatty liver in male rat. Der Pharma Chemica, 8(1), 244-247.

Turner, B., Mølgaard, C., \& Marckmann, P. (2004). Effect of garlic (Allium sativum) powder tablets on serum lipids, blood pressure and arterial stiffness in normo lipidaemic volunteers: a randomised, double blind, placebo-controlled trial. British Journal of Nutrition, 92, 701-706. https://doi.org/10.1079/BJN20041255

Warshafsky, S., Kamer, R. S., \& Sivak, S. L. (1993). Effect of garlic on total serum cholesterol. A metaanalysis. Annals of Internal Medicine,119(7 Pt1), 599-605. https://doi.org/10.7326/0003-4819-1197_Part_1-199310010-00009

Williamson, J., \& Davison, G. (2020). Targeted antioxidants in exercise-induced mitochondrial oxidative stress: emphasis on DNA damage. Antioxidants, 9(11), 1142. https://doi.org/10.3390/antiox9111142

Wood, P. D., Stefanick, M. L., Williams, P. T., \& Haskell, W. L. (1991). The effects on plasma lipoproteins of a prudent weight-reducing diet, with or without exercise, in overweight men and women. The New England Journal of Medicine, 325, 461-466. https://doi.org/10.1056/NEJM199108153250703

Xu, Y., Guo, W., Zhang, C., Chen, F., Tan, H. Y., Li, S., Wang, N., \& Feng, Y. (2020). Herbal medicine in the treatment of non-alcoholic fatty liver diseases-efficacy, action mechanism, and clinical application. Frontiers in Pharmacology, 11, 601. https://doi.org/10.3389/fphar.2020.00601 
Yang, Y., Chan, S. W., Hu, M., Walden, R., \& Tomlinson, B. (2011). Effects of some common food constituents on cardiovascular disease. ISRN Cardiology, 2011, 397136. https://doi.org/10.5402/2011/397136

Yoon, G. (2006). Effect of garlic supplement and exercise on plasma lipid and antioxidant enzyme system in rat. The Korean Journal of Nutrition, 39(1): 3-1.

\section{(c) $(1) \Theta$}

This work is licensed under a Attribution-NonCommercial-NoDerivatives 4.0 International (CC BY-NC-ND 4.0). 